\title{
PERCEPÇÃO FEMININA SOBRE A DENGUE E SEU AGENTE TRANSMISSOR AEDES AEGYPTI (DIPTERA: CULICIDAE) NO BAIRRO VILA OPERÁRIA DE HORIZONTINA/RS
}

\author{
Janaína Daiana Bender ${ }^{1}$ \\ Vidica Bianchi
}

\begin{abstract}
RESUMO
0 presente estudo exibe uma análise do que sabem as mulheres, moradoras do Bairro Vila Operária da cidade de Horizontina/RS, no que diz respeito à dengue e à conscientização para o combate do seu transmissor, o mosquito Aedes aegypti (Diptera: Culicidae). Para o desenvolvimento do estudo foi empregada a abordagem qualitativa e quantitativa, por meio de pesquisa de campo e revisão bibliográfica. Desenvolveu-se a pesquisa utilizando dois questionários, um estruturado com questões de múltipla escolha e outro semiestruturado, dirigidos a 50 pessoas da população feminina, moradoras das Ruas Duque de Caxias, Piratini, Capitão Werland e Navegantes, pertencentes ao Bairro Vila Operária da cidade de Horizontina/RS. Todas as mulheres entrevistadas afirmaram já ter ouvido falar em dengue. A maioria sabe que o mosquito da dengue se cria por meio de larvas que são depositadas na água. Destacam que a doença é perigosa pelo fato de causar transtornos e até morte no indivíduo. Conclui-se que as mulheres possuem conhecimento sobre a prevenção ao mosquito transmissor da dengue e que a equipe da Vigilância Ambiental da Secretaria Municipal de Saúde de Horizontina faz constantes trabalhos de combate ao mosquito, visitas e orientações para a população. Esta ação é considerada essencial pelas mulheres entrevistadas, mas não suficiente para o combate à dengue.
\end{abstract}

Palavras-chave: Percepção feminina. Doença. Mosquito.

PERCEPTION FEMALE ON DENGUE AND HIS AGENT TRANSMITTER AEDES AEGYPTI(DIPTERA: CULICIDAE) IN VILLAGE NEIGHBORHOOD WORKING HORIZONTINA/RS

\begin{abstract}
The Present study shows an analysis of what to know women that lives of Operária Village city Horizontina, with regard to Dengue and awareness for the fight of your transmitter, the mosquito Aedes aegypti (Diptera: Culicidae). To study the development of qualitative and quantitative approach through field research and literature review was used. Developed the survey using two questionnaires a structured multiple-choice questions and one semi-structured, targeted at the female population 50 people, living in the streets, Duque de Caxias, Piratini, CapitãoWerland and Navegantes, belonging to the Operária Village city Horizontia/RS. All the women interviewed said they hadheard of dengue. Most say that the denque mosquito is created by larvae that are deposited in the water. Emphasize that the disease is dangerous because cause inconvenience and even death in the individual. We conclude that women have knowledge about the prevention of mosquito that transmits dengue and that the staff of Environmental Monitoring of the Municipal Health Horizontia makes constant work to combat the mosquito, visits and guidelines for the population. This is considered essential by the women interviewed, but not enough to combat dengue.
\end{abstract}

Keywords: Women perception. Disease. Gnat.

\footnotetext{
${ }^{1}$ Acadêmica do curso Ciências Biológicas. Departamento de Ciências da Vida (DCVida) da Universidade Regional do Noroeste do Estado do Rio Grande do Sul (Unijuí). janabender_2011@hotmail.com

${ }^{2}$ Professora do curso de Ciências Biológicas do Departamento de Ciências da Vida (DCVida) da Universidade Regional do Noroeste do Estado do Rio Grande do Sul (Unijuí). vidica.bianchi@unijui.edu.br
} 
A dengue é uma doença transmitida pela fêmea do mosquito Aedes aegypti (Diptera: Culicidae) ao picar os seres humanos, e vem se alastrando pelos mais diversos locais. Por se tratar de uma doença que traz transtornos à população humana, deve ser combatida, e a melhor maneira é pelo controle do vetor por meio do manejo correto do ambiente, ou seja, eliminando os focos de reprodução.

De acordo com Pinheiro e Corber (1997), desde o século 18 as Américas registram a ocorrência de casos esporádicos de dengue e FHD (Febre Hemorrágica da Dengue) em seus países. A partir da década de 60 observou-se uma mudança no comportamento epidemiológico da doença em consequência da introdução do sorotipo viral DEN-2 e 3 e da ocorrência de surtos de alta magnitude em vários países.

O vetor da dengue é uma espécie de inseto originária da África e foi descrito no Egito. O mosquito invadiu o Brasil no período colonial e foi considerado erradicado do país, porém a reinfestação do Aedes aegypti sempre ocorria porque os países vizinhos não o erradicavam. Hoje, o mosquito é considerado um vetor cosmopolita (Nunes, 2008, p. 18 apud Consoli; Oliveira 1994).

Conforme Dias et al. (2010), no Brasil a primeira epidemia da doença ocorreu entre 1981-1982, na cidade de Boa Vista, Roraima. Logo depois, em 1986-1987, surgiu uma epidemia no Rio de Janeiro. Mais tarde foram documentados vários casos de epidemias em diversos Estados, porém o maior número de casos da doença deu-se em 2002, considerado o ano coma maior incidência, pois foram notificados cerca de 700 mil casos de dengue clássica. Nos anos 2003 e 2004, houve uma diminuição dos casos da doença, voltando a aumentar em 2005.

Segundo Chiaravalloti et al. (2003), entre as doenças vetoradas a dengue merece atenção porque, mesmo na forma clássica, gera transtornos físicos para a população, além de grandes volumes de recursos financeiros na tentativa de seu controle. Quanto à forma grave, há o risco de ocorrência de óbitos gerando altos custos para o setor de saúde. Para Lefévre et al. (2004), quando se trata de saúde pública pouco ou quase nada se consegue sem a participação de todos. Essa participação, no caso da dengue, refere-se à incorporação do conhecimento sobre a doença não somente pela população em geral, mas também pelos diversos setores da sociedade responsáveis pela produção de materiais descartáveis, que podem se tornar criadouros do mosquito.

Chiaravalloti et al. (2003) também observam que, desde a década de 80 , o Brasil vem promovendo inúmeros programas de erradicação para reduzir as ocorrências de epidemias e da mortalidade por dengue. As ações e estratégias, muitas vezes não diferenciadas, de intervenção do poder público, não consideravam as realidades locais, tendo como premissa importante a aplicação de inseticidas para a erradicação do vetor.

Conforme Santos (2008), os programas nacionais de erradicação do vetor, até o ano de 1996, estavam sob o comando da Fundação Nacional da Saúde (Funasa), cujo método utilizado resumia-se ao combate químico, e não correspondia à melhoria da situação da doença, havendo pouca ou nenhuma participação comunitária.

Em agosto de 2001 o Ministério da Saúde lançou o Plano de Intensificação das Ações de Controle da Dengue (PIACD), que incorporou elementos como a mobilização social e a participação comunitária (Brasil, 2002). Neste cenário epidemiológico, o Ministério da Saúde instituiu em 2002 o Programa Nacional de Controle da Dengue (PNCD) (Braga; Valle, 2007), com intensificação das ações dos programas anteriores para a redução do impacto da dengue no Brasil. O plano incorpora as lições das experiências nacionais e internacionais de controle da dengue e enfatiza a necessidade de mudança nos modelos já adotados, inserindo o componente educativo nas medidas de controle; passa, também, a divulgar ações de educação em saúde e mobilização social para mudança de comportamento e de hábitos da população (Brasil, 2002).

A dengue é mais comum nos centros urbanos, onde ocorre a maior incidência de criadouros naturais ou de criadouros resultantes da ação humana, ou seja, da desenfreada e desorganizada urbanização (Brasil, 2005). Em razão disso, o vetor da doença, o mosquito Aedes aegypti, vem se expandindo no território gaúcho de forma rápi- 
da, pois a sociedade ainda não toma os cuidados necessários em relação à prevenção da doença $\mathrm{e}$ as orientações que são dadas pelos agentes sanitários não são seguidas de maneira correta, $o$ que dificulta o controle do vetor no nosso Estado. O Aedes aegypti adaptou-se aos hábitos da população e passou a se reproduzir nos ambientes domésticos e peridomésticos, utilizando-se tanto de recipientes que podem acumular água potável quanto de recipientes descartáveis que acumulam água de chuvas, os quais são encontrados nos lixos da cidade (Camara et al., 2007, p. 1).

De acordo com Ribeiro et al. (2006), os casos de dengue eram relatados somente em alguns países e, hoje, são cem países com preocupação epidemiológica. A população está contribuindo para o desenvolvimento de formas imaturas do agente.

Segundo dados da prefeitura de Horizontina (Prefeitura..., 2012), a equipe de combate à dengue na cidade vem realizando um intenso trabalho. Em 2011 foram feitas 28.862 visitas a residências, estabelecimentos comerciais, terrenos baldios e construções, efetuando-se 308 coletas de larvas e, destas, 126 apresentaram resultado positivo para a larva do mosquito transmissor da dengue, o Aedes aegypti. O centro da cidade foi o local com maior índice do mosquito. Os relatórios da equipe também mostram que nos pequenos depósitos com água parada, como pratos de vasos de flores, latinhas de refrigerante e vasilhas de animais de estimação foram encontradas mais larvas.

"De acordo com integrantes da equipe de combate à dengue de Horizontina, é preciso reforçar os cuidados, pois é grande a quantia (sic) de focos do mosquito que estão sendo encontrados no município" (Rádio Vera Cruz, 2012).

Desta forma, diante de tal problemática, pesquisas para entender a percepção atual das mulheres no combate ao mosquito são necessárias. Assim, este estudo poderá servir de instrumento para a obtenção de maiores informações acerca do assunto e pode, futuramente, indicar métodos mais eficientes para o combate do mosquito da dengue na cidade de Horizontina/RS.
Sabe-se que existem várias soluções para o controle populacional do mosquito da dengue que garantem a prevenção da doença e a qualidade de vida da população. A partir do conhecimento das percepções da sociedade é possível encontrar o melhor caminho para controlar o mosquito e então prevenir a doença. Sendo assim, o presente estudo teve como objetivo identificar qual é o conhecimento da população feminina - moradoras do Bairro Vila Operária, da cidade de Horizontina/RS - sobre a dengue e qual o seu grau de consciência sobre o combate ao mosquito Aedes aegypti.

\section{MATERIAL E MÉTODOS}

Horizontina é um município brasileiro do Estado do Rio Grande do Sul localizado na Mesorregião Noroeste Rio-Grandense e na Microrregião de Três Passos, a uma latitude de $27^{\circ} 37^{\prime} 33^{\prime}$ ' Sul e a uma longitude de $54^{\circ} 18^{\prime} 28^{\prime \prime}$ Oeste, estando a 343 metros de altitude. Sua população estimada em 2009 era de 19.131 habitantes para uma área de 228,849 $\mathrm{km}^{2}$. A cidade é conhecida como o "Berço Nacional das Colheitadeiras Automotrizes".

Para a pesquisa foram utilizadas as abordagens qualitativa e quantitativa. A primeira caracteriza-se pela tentativa de uma compreensão detalhada dos significados e características situacionais apresentadas pelas entrevistadas (Lüdke; André, 1986). Para realizar esta investigação foi adotado um questionário (A) semiestruturado com seis questões discursivas: Você já ouviu falar em dengue?; Como esta doença é transmitida?; Você sabe como e onde o mosquito da dengue se desenvolve?; A Secretaria Municipal da Saúde esta tentando há alguns anos controlar a dengue. Na sua opinião, eles estão conseguindo fazer isso ou não? Por quê?; Na sua opinião, a dengue tem alguma coisa a ver com o lixo? Fale um pouco sobre isso; Você acha que a população poderia colaborar mais no controle da dengue?

Outro questionário (B) estruturado com dez questões objetivas: Qual é a sua idade?; Sua escolaridade?; Você já ouviu falar em dengue?;Na 
sua opinião a dengue é uma doença perigosa ou não? Por quê?; Você sabe como o mosquito da dengue se cria?; A Secretaria da Saúde vem tentando controlar a ocorrência dos mosquitos, visitando as residências. Na sua opinião, eles estão conseguindo fazer isto, ou não?; Você acha que a população contribui para o controle do mosquito?; Para você, o que é mais importante no combate ao mosquito da dengue?; Na sua opinião, a dengue tem a ver com o lixo?; O que você faz na sua casa para combater o mosquito? Estes questionários foram aplicados com $\mathrm{o}$ intuito de analisar o que sabem sobre a dengue e seu transmissor, o Aedes aegypti.

Foram sorteadas quatro ruas do Bairro Vila Operária da cidade de Horizontina/RS: Rua Duque de Caxias, Rua Piratini, Rua Capitão Werland e Rua Navegantes. Foram feitas visitas em todas as casas em que havia mulheres, obtendo-se uma amostra de 50 entrevistadas. Elas foram previamente consultadas e se interessaram em participar da entrevista, autorizando o uso dos resultados em publicações científicas mediante assinatura do Termo de Consentimento Livre e Esclarecido. O projeto foi submetido ao Comitê de Ética em Pesquisa da Unijuí e aprovado pelo protocolo 354.880 .

A análise qualitativa das respostas foi feita mediante a Análise Textual Discursiva, de Moraes e Galliazzi (2007), e na análise quantitativa foi usada a estatística descritiva e apresentada em Figuras e um Quadro.

\section{RESULTADOS E DISCUSSÃO}

Pela análise das respostas dos questionários submetidos às moradoras do Bairro Vila Operária da cidade de Horizontina, foi possível perceber o conhecimento da população feminina sobre a dengue e qual é o grau de consciência das entrevistadas no que diz respeito ao combate ao mosquito transmissor.

Cinquenta mulheres foram entrevistadas no Bairro Vila Operária. A análise das respostas objetivas revela, no que diz respeito à faixa etária, que a maioria das entrevistadas tinha acima de 42 anos, correspondendo a $58 \%$ da amostra. Verificou-se que $8 \%$ das mulheres estavam na faixa entre 12 e 21 anos, $16 \%$ na faixa de 22 a 31 anos e $18 \%$ entre 32 e 41 anos. Quanto à escolaridade, foi observado que o público estudado possuía baixa escolaridade, e a maioria das mulheres tinha apenas o Ensino Fundamental completo, correspondendo a $46 \%$ da amostra; 36\% possuem o Ensino Médio completo e somente 14\% o Ensino Superior completo; ainda 4\% possuem Pós-Graduação completa (Figura 1 A e B).

Figura 1 - (A) Idade e (B) escolaridade da população feminina entrevistada no Bairro Vila Operária da cidade de Horizontina/RS em agosto e setembro de 2013
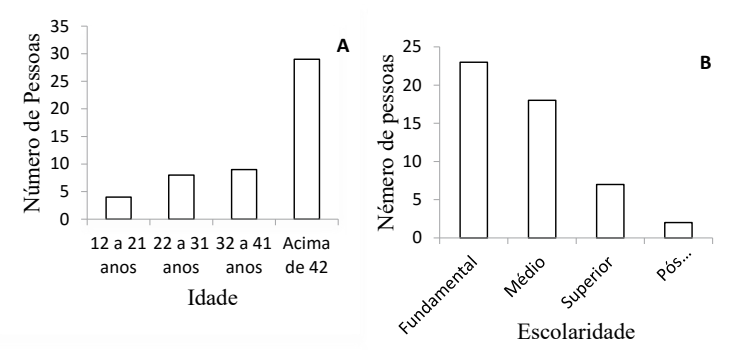

Pode-se observar, também, que todas as mulheres entrevistadas já ouviram falar em dengue. Quando foram questionadas se a dengue é uma doença perigosa ou não, (74\%), afirmaram que sim, porque causa a morte do indivíduo; apenas uma mulher ( $2 \%$ ) afirmou que a dengue é uma doença perigosa porque já ouviu falar sobre ela e $24 \%$ responderam que a doença é perigosa porque produz sintomas graves (Figura $2 \mathrm{~A}$ e B).

Figura 2 - Respostas da população pesquisada no Bairro Vila Operária da cidade de Horizontina/RS em agosto e setembro de 2013, sobre as questões (A) se já ouviu falar em dengue e (B) se a Dengue é uma doença perigosa

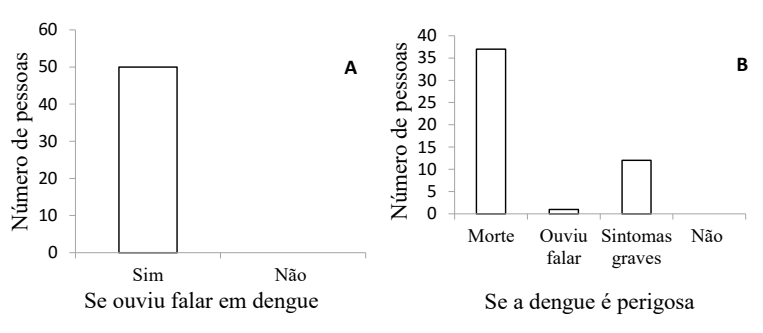


Com relação ao conhecimento sobre como o mosquito da dengue se cria, podemos notar que apenas $4 \%$ das mulheres responderam que o mosquito se cria em água suja acumulada dentro de recipientes, 54\% afirmam que o mosquito se cria por meio de larvas que são depositadas na água e $42 \%$ responderam que o mosquito da dengue se cria em água acumulada ou parada (Figuras 3 e 4).

Figura 3 - Respostas da população feminina pesquisada no Bairro Vila Operária da cidade de Horizontina/RS em agosto e setembro de 2013 sobre como o mosquito da Dengue se cria.

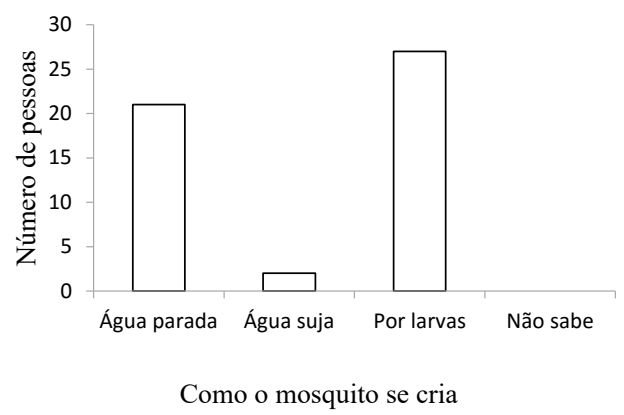

Figura 4-Respostas da população feminina pesquisada no Bairro Vila Operária da cidade de Horizontina/ RS em agosto e setembro de 2013, referente a se a Secretaria da Saúde está conseguindo controlar a ocorrência dos mosquitos realizando visitas às residências

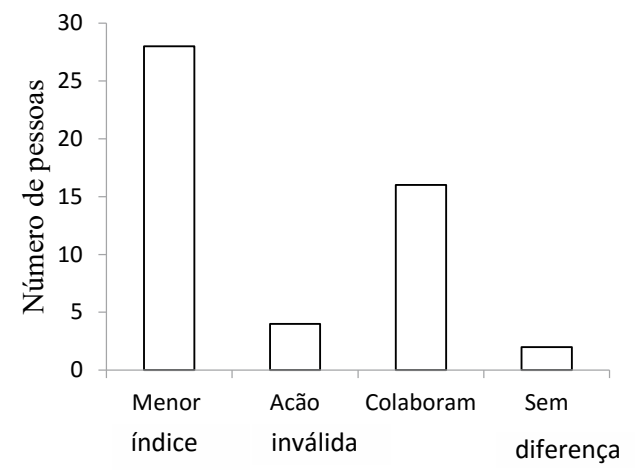

Se a secretaria está controlando a dengue

Quanto às respostas à pergunta que diz respeito a como o mosquito da dengue se cria, a maioria das mulheres não expressou um conhecimento adequado sobre o assunto e respondeu que o mosquito se cria por meio de larvas que são depositadas na água. Segundo estudos do ciclo de vida do A. aegypti, a afirmação não é correta, pois os ovos são colocados pela fêmea na água iniciando-se o desenvolvimento do mosquito.
"A seleção do local de oviposição por parte das fêmeas é o principal fator responsável pela distribuição dos mosquitos nos criadouros e é da maior relevância para a distribuição das espécies na natureza" (Jobling, 1935; Snow, 1971 apud Consoli; Oliveira, 1994, p. 46).

No que diz respeito à população, se está contribuindo para o controle do mosquito ou não, a maioria das mulheres, representando $86 \%$, afirmam que a população colabora, mas que seria necessário mais contribuição; $8 \%$ destacam que a população realiza ações de controle ao mosquito, e apenas $4 \%$ do total responderam que a população não está nem um pouco preocupada. Foi levantado um questionamento sobre o que seria mais importante no combate ao mosquito da dengue. Do total de moradoras entrevistadas, $58 \%$ afirmam que o que seria mais importante no combate ao mosquito é não deixar água parada nas vasilhas que ficam embaixo dos vasos de plantas, $26 \%$ da amostra afirmam que o mais importante no combate ao mosquito seria deixar as caixas d'água sempre limpas e fechadas e $14 \%$ dizem que o mais importante é não deixar água parada em pneus fora de uso; destaca-se que apenas uma mulher, representando $2 \%$, disse que o mais importante é que as piscinas devem ter tratamento da água com cloro (Figura 5 e 6).

Figura 5 - Respostas da população feminina pesquisada no Bairro Vila Operária da cidade de Horizontina/RS em setembro de 2013, referente a se a população contribui para o controle do mosquito

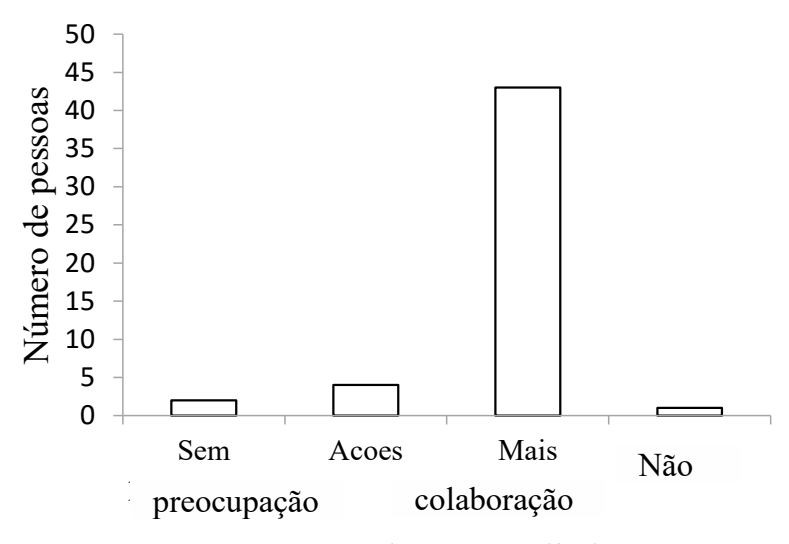

Se a população contribui 
Figura 6 - Respostas da população feminina pesquisada no Bairro Vila Operária da cidade de Horizontina/RS em setembro de 2013, sobre o que seria mais importante no combate ao mosquito da dengue.

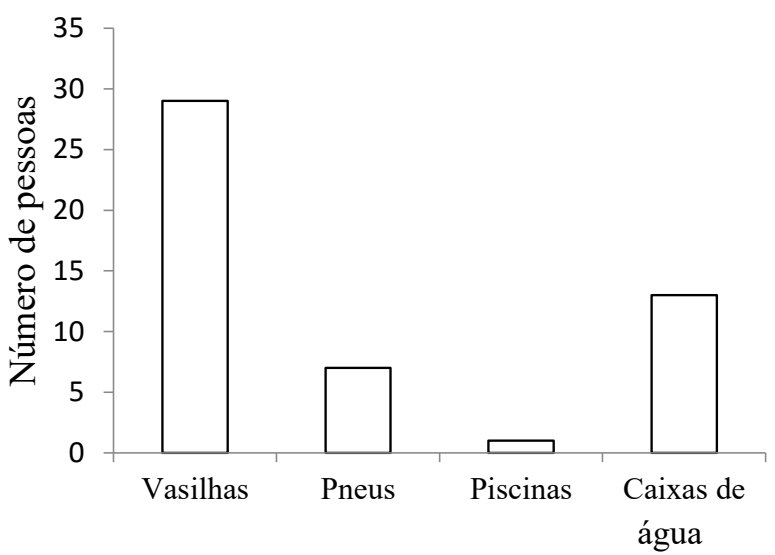

O que é mais importante no combate

Quanto à percepção se a dengue teria alguma coisa a ver com o lixo, a maioria das mulheres, representando $84 \%$ da amostra, afirma que sim, que no lixo há criadouros do mosquito, $6 \%$ responderam que sim, pois o mosquito da dengue cria-se na sujeira e $10 \%$ responderam que a dengue não tem nada a ver com o lixo, pois os mosquitos reproduzem-se em água limpa. Em relação a contribuir para prevenir a dengue no município, $58 \%$ das moradoras declararam não deixar água parada em recipientes e $40 \%$ afirmam que evitam lixos espalhados. Apenas $4 \%$ das mulheres disseram que limpam sempre que possível as caixas d'água (Figuras 7 e 8).

Figura 7 - Respostas da população feminina pesquisada no Bairro Vila Operária da cidade de Horizontina/RS em setembro de 2013, referente a se a dengue tem alguma coisa a ver com o lixo

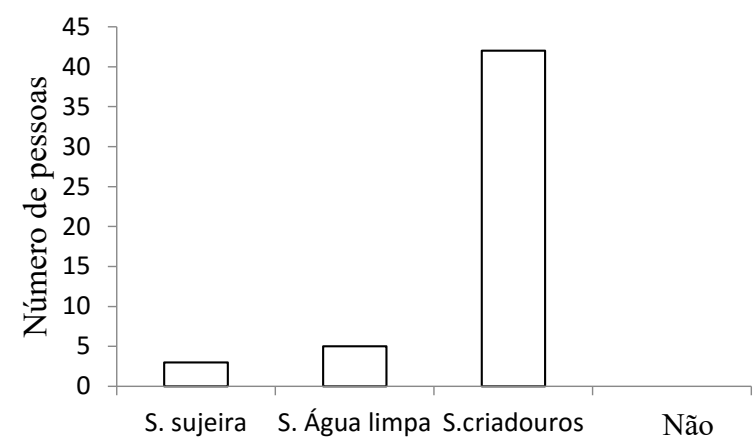

Se a dengue tem a ver com o lixo
Figura 8 - Respostas da população feminina pesquisada no Bairro Vila Operária da cidade de Horizontina/RS em setembro de 2013, sobre o que é feito em casa para combater o mosquito da dengue

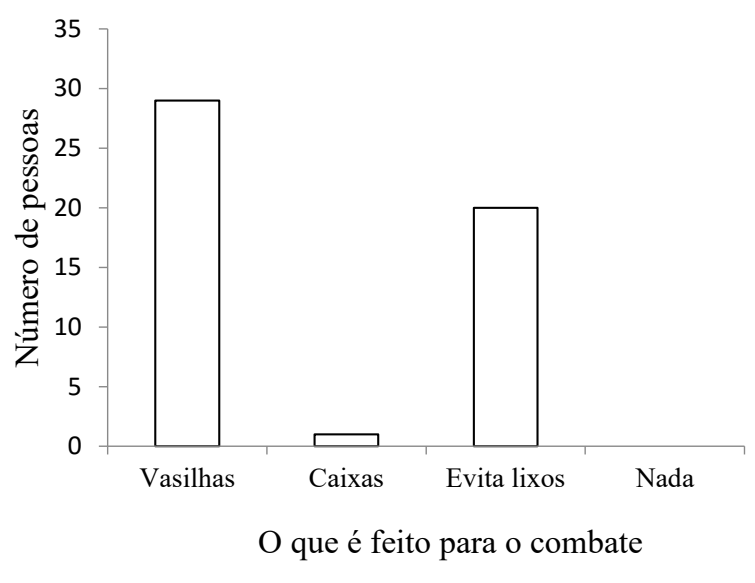

Em relação às respostas do questionário semiestruturado, $100 \%$ das mulheres entrevistadas afirmam já ter ouvido falar em dengue. A maioria delas ressaltou que a doença é transmitida pela picada do mosquito. Quando questionadas sobre como o mosquito da dengue se desenvolve, a maior parte respondeu que o mosquito se desenvolve em água parada (Quadro1).

Nota-se que as ações da Secretaria municipal da saúde estão sendo eficientes para o controle da dengue, pois a população está atenta graças às visitas frequentes e às orientações, mas destaca-se também que algumas mulheres dizem que ainda falta monitoramento em terrenos abandonados e colaboração dos agentes, pois os focos do mosquito continuam, e também sugerem que a população deve cooperar mais.

De acordo com Mafra e Lemos (2009), a participação dos profissionais de saúde é de importância basilar no combate à dengue. Atuando como agentes de mobilização social, contribuem para a mudança de cultura dos cidadãos, que precisam assumir cada vez mais o papel de protagonistas do cuidado de sua própria saúde. Trabalhando no diagnóstico e no tratamento da dengue, reconhecem os casos, estratificam os riscos e realizam a intervenção adequada, encaminhando, quando necessário, o cidadão para o ponto correto de atenção à saúde. 
Para Pignatti (2013), a população ainda acredita que para minimizar a ocorrência de dengue é necessário somente o trabalho dos agentes sanitários, realizando as visitas às residências, eliminando focos dos mosquitos e orientando os moradores em relação à prevenção da doença e dos criadouros. O problema é que os moradores deixam de fazer a sua parte, delegando a responsabilidade de eliminar os focos do mosquito apenas aos agentes quando estes vão as suas casas; ficam esperando e, por isso, não cuidam dos seus pátios, o que contribui para a proliferação do $A$. aegypti.

O estudo também evidencia que a maioria das mulheres entrevistadas afirmou que a dengue tem a ver com o lixo quando este contiver água parada, sendo este um ponto positivo, pois o lixo é um dos grandes vilões para a proliferação do mosquito; qualquer tampa de garrafa pet jogada pode ser um criadouro potencial. Quando questionadas se a população poderia colaborar mais no controle à dengue, a maior parte respondeu que sim, com certeza. Percebe-se que este segmento da sociedade tem a informação dos problemas relacionados ao lixo e à dengue, porém parece não ter consciência suficiente para mudar de atitude e se envolver nas ações comunitárias de prevenção.

No entendimento de Mota (2003,), a maioria das cidades brasileiras ainda utiliza a forma de depositar os resíduos sólidos em depósitos a céu aberto. Alves et al. (2007) afirmam que tal alternativa, conhecida por lixão, caracteriza-se pela simples descarga dos resíduos sólidos sobre o solo, sem medidas de proteção ao meio ambiente ou à saúde pública.

Ainda, nesse sentido, Castilhos Júnior et al. (2006) expõem que o depósito de resíduos sólidos a céu aberto ou lixão é uma forma de deposição desordenada, sem compactação ou cobertura dos resíduos, o que propicia a poluição do solo, ar e água, bem como a proliferação de vetores de doenças.
Quadro 1 - Respostas do questionário semiestruturado

\begin{tabular}{|c|c|}
\hline & Respostas \\
\hline $\begin{array}{l}\text { 1. Se já ou- } \\
\text { viu falar em } \\
\text { dengue. }\end{array}$ & $50(100 \%)$ ouviram falar em dengue. \\
\hline $\begin{array}{l}\text { 2. Transmis- } \\
\text { são da doença }\end{array}$ & $\begin{array}{l}49(98 \%) \text { disseram que é transmitida pelo mosquito } \\
\text { ou pela picada. } \\
1(2 \%) \text { respondeu que é pela larva do mosquito. }\end{array}$ \\
\hline $\begin{array}{l}\text { 3. Desenvol- } \\
\text { vimento do } \\
\text { mosquito }\end{array}$ & $\begin{array}{l}1(2 \%) \text { respondeu que o desenvolvimento do mos- } \\
\text { quito ocorre em etapas: ovo, larva, pupa, adulto. } \\
42(84 \%) \text { falaram que o mosquito se desenvolve } \\
\text { em água parada. } \\
4(8 \%) \text { responderam que se desenvolve em água } \\
\text { limpa e parada. } \\
3(6 \%) \text { disseram que é em água limpa. }\end{array}$ \\
\hline $\begin{array}{l}\text { 4. Opinião } \\
\text { das entrevis- } \\
\text { tadas sobre } \\
\text { as ações da } \\
\text { Secretaria } \\
\text { Municipal da } \\
\text { Saúde }\end{array}$ & $\begin{array}{l}3(6 \%) \text { responderam que não; que a ação não está } \\
\text { sendo eficiente, que é necessário um constante } \\
\text { monitoramento de terrenos baldios e casas aban- } \\
\text { donadas. } \\
1(2 \%) \text { respondeu que eles estão conseguindo, } \\
\text { pulverizando as propriedades e conscientizando as } \\
\text { pessoas. } \\
1 \text { ( } 2 \%) \text { respondeu que não estão conseguindo, pois } \\
\text { deveriam deixar veneno para cada morador, sendo } \\
\text { assim mais fácil o combate do mosquito. } \\
18(36 \%) \text { falaram que estão conseguindo, pois a } \\
\text { população está atenta graças às visitas frequentes e } \\
\text { às orientações. } \\
1(2 \%) \text { respondeu que estão conseguindo, pois a } \\
\text { atuação tem contribuído de forma significativa para } \\
\text { a melhoria da saúde no município. } \\
2(4 \%) \text { responderam que estão conseguindo, pois } \\
\text { diminuiu o índice de mosquito e da dengue. } \\
6(12 \%) \text { responderam que eles estão conseguindo, } \\
\text { pois não há caso de doença no bairro e na cidade. } \\
1(2 \%) \text { respondeu que ainda faltam cuidados, mas } \\
\text { que está ajudando bastante. } \\
7(14 \%) \text { responderam que está sendo eficiente, mas } \\
\text { é a população quem deve colaborar. } \\
2(4 \%) \text { responderam que sim, mas ainda tem mui- } \\
\text { tos terrenos vazios e abandonados que deveriam ser } \\
\text { vistos, com muitos entulhos com água parada. } \\
3(6 \%) \text { responderam que não, pois o morador é } \\
\text { responsável pelo seu pátio. } \\
3(6 \%) \text { que não, pois as visitas deveriam ser mais } \\
\text { frequentes. } \\
2(4 \%) \text { responderam que não, pois ainda existe } \\
\text { foco do mosquito. }\end{array}$ \\
\hline $\begin{array}{l}\text { Se tem } \\
\text { alguma coisa } \\
\text { a ver com o } \\
\text { lixo }\end{array}$ & $\begin{array}{l}1(2 \%) \text { respondeu que sim, que o lixo é o grande } \\
\text { vilão da epidemia de dengue. } \\
2(4 \%) \text { falaram que no lixo orgânico malcuidado } \\
\text { vem mosquito. } \\
4(8 \%) \text { responderam que sim, se o lixo ficar muito } \\
\text { tempo parado e acumulado. } \\
2(4 \%) \text { falaram que sim, que no lixo há criadouros } \\
\text { do mosquito, onde se acumula água parada. } \\
28(56 \%) \text { disseram que sim, o lixo que tiver água } \\
\text { parada. } \\
2(4 \%) \text { responderam que sim, por que onde existe } \\
\text { lixo há focos do mosquito. } \\
2(4 \%) \text { respondeu que sim, que é necessário separar } \\
\text { e reciclar o lixo, senão ele se acumula e aparece o } \\
\text { mosquito. } \\
1(2 \%) \text { respondeu que sim, se tiver lixo abando- } \\
\text { nado. } \\
5(10 \%) \text { responderam que sim, que é no lixo que o } \\
\text { mosquito se desenvolve. } \\
3(6 \%) \text { responderam que não; que o mosquito se } \\
\text { desenvolve na água limpa. }\end{array}$ \\
\hline
\end{tabular}




\begin{tabular}{|l|l|}
\hline $\begin{array}{l}\text { 6. Se a } \\
\text { população } \\
\text { poderia cola- } \\
\text { borar mais no } \\
\text { controle da } \\
\text { dengue }\end{array}$ & $\begin{array}{l}1(2 \%) \text { respondeu que sim, que a população pode } \\
\text { colaborar mais ao desenvolver simples hábitos que } \\
\text { eliminam o mosquito. }\end{array}$ \\
& $\begin{array}{l}\text { sem mais não haveria dengue. } \\
28(56 \%) \text { responderam que sim, poderia ou com } \\
\text { certeza. } \\
5(10 \%) \text { responderam que poderia, pois tem pes- } \\
\text { soas que não cuidam. } \\
1(2 \%) \text { respondeu que com certeza, pois o controle } \\
\text { da dengue exige um esforço de todos. } \\
7(14 \%) \text { disseram que sim; se cada um cuidasse do } \\
\text { seu terreno seria o suficiente. } \\
1(2 \%) \text { respondeu que bem mais; que deveria ser } \\
\text { multado quem não colaborasse. } \\
1(2 \%) \text { falou que sim, cuidando com os pratos } \\
\text { embaixo das plantas, não largando lixo em volta. } \\
3(6 \%) \text { responderam que sim, cuidando das águas } \\
\text { paradas. }\end{array}$ \\
\hline
\end{tabular}

Segundo Tauil (2001, p. 3), para o controle da dengue é importante a incorporação de determinados hábitos ao cotidiano das populações, como evitar potenciais reservatórios de água em quintais, troca periódica da água de plantas aquáticas e manutenção de piscinas com água tratada, entre outros. Ainda conforme este autor, a estratégia para alcançar estas metas inclui uma intensa mobilização comunitária por todos os meios de comunicação modernos e um processo continuado e sustentado de educação em saúde.

Conforme Cavalcante, Porto e Tauil (2006, 2007) ressaltam na falta de uma vacina que garanta a imunização das pessoas, o controle da dengue centra-se na quebra da cadeia de transmissão da doença e, portanto, a melhor medida de combate é eliminar os ambientes favoráveis ao desenvolvimento do mosquito $A$. aegypti, os quais se encontram, em sua maioria, dentro dos domicílios. Uma das alternativas viáveis para o controle seria a mobilização e a colaboração da comunidade na manutenção de suas residências livres de potenciais criadouros do vetor. A participação da comunidade não apenas contribui para o controle da dengue, mas também permite desenvolver atitudes e práticas saudáveis que melhoram a higiene do ambiente doméstico.

A população pesquisada também acredita que o controle da dengue pode ocorrer pela contenção do mosquito, monitorando os ambientes em que ele pode se reproduzir. Constata-se que esta população tem a informação clara sobre a importância do controle do $A$. aegypti e também demonstra ter consciência e responsabilidade quanto ao cuidado com o ambiente.

\section{CONSIDERAÇÕES FINAIS}

As entrevistas realizadas com as mulheres donas de casa do bairro em estudo mostraram que estas possuem um nível satisfatório de informação sobre a dengue. A maioria soube relatar de forma correta como ocorre a transmissão da doença, bem como a importância dos recipientes contendo água parada para a proliferação do $A$. aegypti, realizando medidas de controle e prevenção dessa enfermidade.

Por mais que a equipe da vigilância ambiental da Secretaria Municipal de Saúde de Horizontina faça constantes trabalhos de combate ao mosquito, visitando as residências e dando orientações para a população, algumas mulheres responderam que ainda faltam vários cuidados, por isso pode-se afirmar que o presente estudo oferece à Secretaria de Saúde do município pesquisado informações úteis, que poderão servir de base para uma melhor estruturação dos programas voltados à prevenção da dengue.

Com a realização desta pesquisa foi possível observar que as mulheres possuem bastante conhecimento sobre a prevenção do mosquito transmissor da dengue. Elas cuidam bem das suas casas e eliminam todo e qualquer ambiente em que o mosquito A. aegypti possa se desenvolver.

\section{REFERÊNCIAS}

ALVES, C. B. et al. Resíduos sólidos urbanos como insumo à produção de energia. SEMINÁRIO NACIONAL DE RESÍDUOS SÓLIDOS, 8., Associação Brasileira de Engenharia Sanitária e Ambiental, São Luís, 2007.

BRAGA, I. A.; VALLE, D. Aedes aegypti: inseticidas, mecanismos de ação e resistência. Epidemiol. Serv. Saúde, Brasília, v. 16, n. 4, dez. 2007. 
BRASIL. Ministério da Saúde. Vigilância epidemiológica. Brasília, DF: Fundação Nacional de Saúde; Programa Nacional de Controle da Dengue, 2002. p. 32.

Ministério da Saúde. Guia de vigilância epidemiológica. 6. ed. Brasília, 2005.

CAMARA, F. P. et al. Estudo retrospectivo (histórico) da dengue no Brasil: características regionais e dinâmicas. Revista da Sociedade Brasileira de Medicina Tropical, Rio de Janeiro, v. 40, n. 2, p. 192-196, mar./abr. 2007.

CASTILHOS JÚNIOR, A. B. et al. Resíduos sólidos urbanos: aterro sustentável para municípios de pequeno porte. Rio de Janeiro: Abes; Rima, 2006. 294 p.

CAVALCANTE, K. R. J. L.; PORTO V. T.; TAUIL, P. L. Avaliação dos conhecimentos, atitudes e práticas em relação à prevenção de dengue na população de São Sebastião. Comum Ciênc Saúde, Brasília, DF, v. 18, n. 2, p. 141-146, 2007.

CHIARAVALLOTI, N. F. et al. Controle do vetor da dengue e participação da comunidade em Catanduva, São Paulo, Brasil. Cadernos de Saúde Pública, v. 19, n. 6, p. 1.739-1.749. 2003.

CONSOLI, R. A. G. B.; OLIVEIRA, R. L. Principais mosquitos de importância sanitária no Brasil. [on-line]. Rio de Janeiro: Editora Fiocruz, 1994. 228 p. Disponível em: AvailablefromSciELO Books: <http://books.scielo. org $>$.

DIAS L. B. A. et al. Dengue: transmissão, aspectos clínicos, diagnóstico e tratamento. $\mathrm{Me}$ dicina, Ribeirão Preto, Brasil, 43(2): 143-52, 2010.

JORNAL SEMANAL. Chuva aumenta o risco de epidemia de dengue. Disponível em: $<\mathrm{http}: / /$ www.jsemanal.com.br/965-chuva-aumenta-o-risco-de-epidemia-de-dengue>.

LEFÉVRE F. et al. Representações sociais sobre relações entre vasos de plantas e o vetor da dengue. Revista de Saúde Pública, 38, p. 405-414, 2004.

LÜDKE, M.; ANDRÉ, M. E. D. A. Pesquisa em educação: abordagens qualitativas. São Paulo: Ed. EPU, 1986.
MAFRA, A. A.; LEMOS, L. F. Linha-guia de atenção à saúde. 1. ed. Belo Horizonte: Governo de Minas, 2009.

MORAES, R.; GALIAZZI, M. C. Análise textual discursiva. Ijuí: Ed. Unijuí, 2007. p. 571.

MOTA, S. Introdução à engenharia ambiental. 3. ed. Rio de Janeiro: Abes, 2003.

PIGNATTI, Marta G. Politicas ambientais e saúde: as práticas sanitárias para o controle da dengue no ambiente urbano. Instituto de Saúde Coletiva. Cuiabá. Disponível em: $<\mathrm{http}$ ://bvsde. paho.org/bvsacd/cd25/politicas.pdf $>$. Acesso em: 13 nov. 2013.

PINHEIRO, F. P.; CORBER, S. J. Situação global de dengue, febre hemorrágica da dengue e seu aparecimento nas Américas. World Health Stat, Q 50, p. 161-169, 1997.

PREFEITURA MUNICIPAL DE HORIZONTINA. Trabalho de combate à dengue é intenso em Horizontina. 2012. Disponível em: <http:// www.pmhorizontina.com.br/portal/index. php?option $=$ com_content $\&$ task $=$ view $\& \mathrm{id}=10$ $42 \&$ Itemid $=48>$.

RÁDIO VERA CRUZ. Número de focos da dengue aumentou em Horizontina. 2012. Disponível em: <http://guiadasnoticias.com.br/index.php?origem $=$ noticias_de-talhes\&id=9345>.

RIBEIRO, A. F. et al. Associação entre incidência de dengue e variáveis climáticas. Rev. Saúde Pública, São Sebastião, SP, Brasil, 40(4), p. 671-676, 2006.

SANTOS, M. A. V. M. Aedes aegypti (Diptera: Culicidae): estudos populacionais e estratégias integradas para controle vetorial em municípios da região metropolitana do Recife, no período de 2001 a 2007. 2008. 218 f. Tese (Doutorado em Saúde Pública) - Centro de Pesquisas AggeuMagalhães, Fundação Oswaldo Cruz, Recife, 2008.

TAUIL, P. L. Urbanização e ecologia da dengue. Cadernos de Saúde Pública, 17, 2001.

Recebido em: 13/2/2015

Aceito em: 7/4/2016 